\title{
Simultaneous determination of five essential amino acids in plasma of Hyperlipidemic subjects by UPLC-MS/MS
}

\author{
Zhibin Chen ${ }^{1 \dagger}$, Feiyan Lin ${ }^{2 \dagger}$, Xuemei Ye ${ }^{3}$, Yuqian Dong ${ }^{4}$, Lufeng $\mathrm{Hu}^{3^{*}}$ and Aifang Huang ${ }^{3^{*}}$
}

\begin{abstract}
Background: Millions of adults have been reported with hyperlipemia in the world. It is still unclear whether the plasma level of essential amino acids (AAs) will be influenced by the hyperlipemia. This study was aimed to investigate the AAs levels and the underlying metabolic relationship in hyperlipidemic subjects.

Methods: An ultra-high performance liquid chromatography-tandem mass spectrometric (UPLC-MS/MS) method was developed for the determination of phenylalanine (Phe), valine (Val), histidine (His), tryptophan (Trp), and methionine (Met). Plasma samples $(100 \mu \mathrm{L})$ were precipitated by acetonitrile $(300 \mu \mathrm{L})$ and analyzed on a BEH C18 $(2.1 \mathrm{~mm} \times 100 \mathrm{~mm}, 1.7 \mu \mathrm{m})$ column at $40^{\circ} \mathrm{C}$ by gradient elution. The mobile phase composed of $0.1 \%$ formic acid and acetonitrile was used with flow rate at 0.2-0.4 ml/0-3 min. Five AAs were determined at positive electrospray ionization (ESI+) at m/z 118.1/72.1 (Val), 150.12/104.02(Met), 156.06/110.05(His), 166.1/120.1(Phe), and 205.2/188.02 (Trp). A total of 75 healthy subjects and 83 hyperlipidemic subjects, who had blood routine test and plasma lipid test were determined by developed UPLC-MS/MS.
\end{abstract}

Results: It was shown that there was good linearity for Val, Met, His, Phe, and Trp within 1-100 $\mu \mathrm{g} / \mathrm{mL}$. The relative standard deviations of precision and accuracy were all within 15\%. The level of Val, Phe, Trp, His, and Met were $35.34 \pm 15.64,22.72 \pm 9.13,17.23 \pm 4.94,16.78 \pm 13.64$, and $6.24 \pm 1.97 \mu \mathrm{g} / \mathrm{mL}$ in healthy subjects, while they were $38.04 \pm 16.70,22.41 \pm 8.45,15.62 \pm 5.77,18.35 \pm 14.49$, and $6.21 \pm 1.97 \mu \mathrm{g} / \mathrm{mL}$ in hyperlipidemic subjects respectively. The Spearman's correlations analysis showed that there were high correlations between Val, Phe, Trp, His, Met and triglyceride in healthy subjects. While, those correlations decreased in hyperlipemia cases.

Conclusion: A convenient and sensitive method for simultaneous determination of Val, Phe, Trp, His, and Met in human plasma was developed. There was a high correlation between Val, Phe, Trp, His, Met and triglyceride. Hyperlipemia influences the metabolic balance of His, Phe, Trp, Met and Val.

Keywords: Amino acid, Human, UPLC-MS/MS, Hyperlipemia, Plasma

\footnotetext{
*Correspondence: hulufeng79@sina.com; mzyf88551@163.com

${ }^{\dagger}$ Zhibin Chen and Feiyan Lin contributed equally to this work.

${ }^{3}$ Department of Pharmacy, The First Affiliated Hospital of Wenzhou Medical

University, Nanbaixiang Street, Ouhai District, Wenzhou 325000, China

Full list of author information is available at the end of the article
}

(c) The Author(s). 2020 Open Access This article is licensed under a Creative Commons Attribution 4.0 International License, which permits use, sharing, adaptation, distribution and reproduction in any medium or format, as long as you give appropriate credit to the original author(s) and the source, provide a link to the Creative Commons licence, and indicate if changes were made. The images or other third party material in this article are included in the article's Creative Commons licence, unless indicated otherwise in a credit line to the material. If material is not included in the article's Creative Commons licence and your intended use is not permitted by statutory regulation or exceeds the permitted use, you will need to obtain permission directly from the copyright holder. To view a copy of this licence, visit http://creativecommons.org/licenses/by/4.0/ The Creative Commons Public Domain Dedication waiver (http://creativecommons.org/publicdomain/zero/1.0/) applies to the data made available in this article, unless otherwise stated in a credit line to the data. 


\section{Introduction}

Amino acid exists in two stereoisomeric forms, L forms and D forms, most of which are L-isomers. The amounts of D-AAs are dramatically low in human body [1]. So far, there are about $500 \alpha$-amino acids were discovered in nature. However, only 20 of them are existed in human being [2]. Among them, 9 essential AAs cannot synthesized in human body, which are phenylalanine (Phe), valine (Val), histidine (His), tryptophan (Trp), methionine (Met), lysine, leucine, isoleucine, and threonine [3]. Essential AAs are the most important essential substances in organisms, which serve as the precursors for synthesis of proteins, various enzymes, hormones, and body fluids, et c [4] Moreover, the essential AAs act as the key regulators of gene expression, and participate in various physiological and pathological processes, such as growth, digestion, and maintenance of the body's immune system [5-7]. Therefore, the study of essential AAs has always been widely concerned in biomedical research.

So far, various analytical methods for quantification of AAs have been reported, such as.

gas chromatography with mass spectrometry (GC-MS) detection [8-10], capillary electrophoresis with contactless conductivity detection [11], UV-absorption detection [12], laser-induced fluorescence detection [13], high performance liquid chromatography (HPLC) with ultraviolet [14] and fluorescence detection [15-17]. Among them, many methods include a derivatization step, such as ethyl chloroformate derivatization [8], methyl chloroformate derivatization [10], trimethylsilyl-trifluoroacyl derivatization [9], since AAs have small molecular weight and strong polarity. However, derivatization is complex and time consuming, and reduces the degree of ionization in the positive ion mode [18]. Compared with GC-MS and HPLC, liquid chromatography tandem with mass spectrometry detection (LC-MS) had higher sensitivity and stability. So far, there several LC-MS methods have been reported [19-23]. However, some methods were used in food [21, 22], some methods had high limits of detection or need derivatization to improve the chromatographic separation $[19,20]$.

Hyperlipemia is a primary and major risk factor for the atherosclerotic cardiovascular diseases. Millions of adults have been reported with elevated total cholesterol (TC) or triglyceride (TG) levels in the world [24, 25]. Although numerous researches have been carried out to study hyperlipemia, it is unclear whether the plasma levels of essential AAs are affected. Therefore, the purpose of this study is to establish a rapid, convenient, and sensitive method for the determination of essential AAs in human plasma without derivatization. Based on the developed UPLC-MS/MS method, the essential AAs levels in healthy subjects and in hyperlipidemic patients were determined and analyzed.

\section{Methods \\ Reagents}

Phe, Val, His, Trp, Met and colchicine (purity >98\%) were bought from Sigma-Aldrich (Lewis, USA) and J\&K Scientific LTD (Peking, China). Acetonitrile, methanol, and formic acid were HPLC graded and bought from Merck Company (Darmstadt, Germany). Ultra-pure water (resistance $>18 \mathrm{~m} \Omega$ ) were provided by a Millipore Milli-Q purification system (Bedford, USA).

\section{Hyperlipidemic and healthy subjects}

The blood samples of hyperlipidemic and healthy subjects were collected from the clinical laboratory of the First Affiliated Hospital of Wenzhou Medical University. The study was carried out in accordance with the Declaration of Helsinki, and approved by the ethics committee of the First Affiliated Hospital of Wenzhou Medical University.

All of these subjects received blood routine test (BRT) and lipid test, which were analyzed by the XE-2100 automated hematology analyzer (Sysmex, Japan) and the Beckman AU5800 biochemical measurement (Beckman Coulter, Inc. USA). After BRT and biochemical test, $100 \mu \mathrm{L}$ of residual plasma was collected and determined by UPLC-MS/MS method.

\section{UPLC-MS/MS conditions}

An ACQUITY UPLC and Xevo TQ-S Micro triple quadrupole mass spectrometer (Waters, USA) was used in this study. Chromatographic separations of His, Met, Trp, Val, Phe and colchicine (internal standard, IS) were separated at a Waters BEH C18 column $(2.1 \mathrm{~mm} \times 100 \mathrm{~mm}, 1.7 \mu \mathrm{m})$, which temperature was set at $40{ }^{\circ} \mathrm{C}$. The mobile phase consisted of $0.1 \%$ formic acid water (solvent $\mathrm{A}$ ), which was prepared by added $0.5 \mathrm{~mL}$ formic acid into $500 \mathrm{~mL}$ water, and acetonitrile (solvent B). The gradient elution of mobile phase began with $A: B=90: 10 \mathrm{v} / \mathrm{v}$, which changed as follows: $A: B=80: 20 \mathrm{v} / \mathrm{v}$ at $1.2 \mathrm{~min}, \mathrm{~A}: \mathrm{B}=10: 90 \mathrm{v} / \mathrm{v}$ at $2.5 \mathrm{~min}$, $A: B=90: 10 \mathrm{v} / \mathrm{v}$ at $3.0 \mathrm{~min}$. The flow rate was set at $0.2 \mathrm{~mL} /$ $\min (0-1.2 \mathrm{~min}), 0.4 \mathrm{~mL} / \mathrm{min}(1.2-2.5 \mathrm{~min}), 0.2 \mathrm{~mL} / \mathrm{min}$ (2.5-3.0 $\mathrm{min})$ respectively. The injection volume was $1 \mu \mathrm{L}$. His, Met, Trp, Val, Phe and IS were detected in the multiple reaction monitoring (MRM) mode.

\section{Sample preparation}

A total of $100 \mu \mathrm{L}$ plasma was added into $1.5 \mathrm{~mL}$ centrifuge tube. After that, the plasma was precipitated by $300 \mu \mathrm{L}$ acetonitrile, which contained $0.1 \mu \mathrm{g} / \mathrm{mL}$ of colchicine (IS). The mixture was put under vortex movement for $0.3 \mathrm{~min}$ and centrifuged at $15000 \mathrm{rpm}$ for $5 \mathrm{~min}$. Finally, $1 \mu \mathrm{L}$ supernatant injection was set for UPLC-MS/MS system analysis. 


\section{Calibration curve}

The mixed stock solution of His, Met, Trp, Val, and Phe was dissolved with water at $1.00 \mathrm{mg} / \mathrm{mL}$, and diluted to $10-500 \mu \mathrm{g} / \mathrm{mL}$. The calibration standards were from 1 to $100 \mu \mathrm{g} / \mathrm{mL}$, which were prepared by spiking $10 \mu \mathrm{L}$ different concentration of mixed AAs standard solutions into $90 \mu \mathrm{L}$ of blank plasma. The final concentrations of added AAs in blank plasma were 1, 2.5, 5, 10, 25, 50, $100 \mu \mathrm{g} /$ $\mathrm{mL}$, which were precipitated by $300 \mu \mathrm{L}$ acetonitrile as mentioned in sample preparation.

\section{Method validation}

The method validation was evaluated by three qualitycontrol (QC) samples at 10,40 , and $80 \mu \mathrm{g} / \mathrm{mL}$, which were prepared as samples of calibration curve.

The intra-day precision and accuracy of His, Met, Trp, $\mathrm{Val}$, and Phe was carried out three replications in a day, and the inter-day precision was evaluated by measuring daily and continuously for 3 days. The concentrations of QC samples were calculated by the calibration curves developed. The precision was expressed as the relative standard deviation (RSD), and the accuracy was expressed as the relative error (RE), which was calculated as: $\mathrm{RSD}=$ Mean $\mathrm{QC} / \mathrm{SD} \times 100 \%$ and $\mathrm{RE}=($ Mean $\mathrm{QC}-\mathrm{QC}) / \mathrm{QC} \times 100 \%$.

The extraction recovery at 10,40 , and $80 \mu \mathrm{g} / \mathrm{mL}$ was evaluated by comparing the peak area to the pure standard solution at the same concentration. The matrix effects were investigated by comparing the peak area of His, Met, Trp, Val and Phe to the extracted sample added with the same concentration of analytes. The stability was evaluated at the room temperature from $2 \mathrm{~h}$ to $24 \mathrm{~h}$.

The robustness of UPLC-MS/MS method was studied in term of mobile phase, $\mathrm{pH}$, column temperature and flow rate at three QC sample concentrations. Those parameters were interchanged within the range of $1-10 \%$ of the developed conditions, while keeping the other parameters unchanged. The peak areas of 5 AAs were recorded. The ruggedness was determined on two different BEH C18 Columns, centrifuges and by two different analysts to perform the overall analysis.

\section{Data analysis}

All data of BRT, lipids indices and five AAs were expressed as mean and standard deviation. Independent sample $t$ test was used to analyze the difference between hyperlipidemic and healthy subjects. The relationships of 5 AAs were analyzed by bivariate correlation. The statistical analysis was carried out by using the statistical software SPSS 17 (IBM, USA).

\section{Results}

\section{Method development and linearity}

In this study, Val, Met, His, Phe, and Trp all had characteristic daughter ions in positive model. The optimal collision energy of five AAs was from 10 to $15 \mathrm{eV}$. If the collision energy was over $20 \mathrm{eV}$, the MS response will decrease. The developed UPLC-MS/MS parameters and mass spectrum are shown in Table 1 and Fig. 1.

According to the selected UPLC-MS/MS condition, the result showed that there was no interfering endogenous substance observed in the UPLC-MS/MS chromatograms (Fig. 2).

The calibration curve was developed by the linear regression of peak area ratios against the concentrations. Since AAs are endogenous substances, their calibration curves were subtracted with the area of a blank sample. The equation of calibration curves were showed in supplement Table 1. The correlation coefficients (R) of His, Met, Trp, Val, Phe were 0.9954, 0.9984, 0.9980, 0.9985, and 0.9942 over the concentration ranges. The lower limit of quantitation was $1 \mu \mathrm{g} / \mathrm{mL}$ for His, Met, Trp, Val and Phe.

\section{Method validation}

The intra-day and inter-day precision and accuracy of His, Met, Trp, Val, Phe at the three QC levels in plasma are presented in Table 2. The results showed that RSD of intra-day and inter-day precision of 5 AAs were all within $15 \%$. RE of accuracy ranged from -7.63 to $12.12 \%$.

The extraction recovery, matrix effect and stability of the five essential AAs are presented in supplement Table 2. The mean extraction recoveries of His, Met, Trp, Val, Phe at three different QC levels were $76.48 \pm 6.88$, $70.10 \pm 5.55, \quad 70.96 \pm 6.47, \quad 73.40 \pm 9.10, \quad 74.46 \pm 10.61$, $72.49 \pm 6.60$, which indicated that there was no obvious difference among the extraction recoveries of His, Met, Trp, Val, Phe. The matrix interference ranged from 62.15 to $84.14 \%$, which indicated that the matrix effect was acceptable. The extract stability showed each QC level below 15\% deviation from initial concentrations, which demonstrated that they were stable in plasma at room temperature for $24 \mathrm{~h}$.

The results of robustness and ruggedness revealed there were no significant changes observed in the chromatographic peaks of 5 AAs. The peak RSD values of mobile phase, $\mathrm{pH}$, column temperature and flow rate

Table 1 UPLC-MS/MS data of five essential AA and colchicine (IS)

\begin{tabular}{llllll}
\hline Compound & $\begin{array}{l}\text { ion } \\
\text { mode }\end{array}$ & $\begin{array}{l}\text { parent ion } \\
(\mathrm{m} / \mathrm{z})\end{array}$ & $\begin{array}{l}\text { daughter } \\
\text { ion }(\mathrm{m} / \mathrm{z})\end{array}$ & Cone $(\mathrm{V})$ & Collision \\
\hline Val & ESI+ & 118.10 & 72.10 & 40 & 15 \\
Met & ESI+ & 150.12 & 104.02 & 40 & 10 \\
His & ESI+ & 156.06 & 110.05 & 40 & 15 \\
Phe & ESI+ & 166.10 & 120.10 & 20 & 15 \\
Trp & ESI+ & 205.20 & 188.02 & 20 & 10 \\
IS & ESI+ & 400.00 & 358.00 & 40 & 20 \\
\hline
\end{tabular}



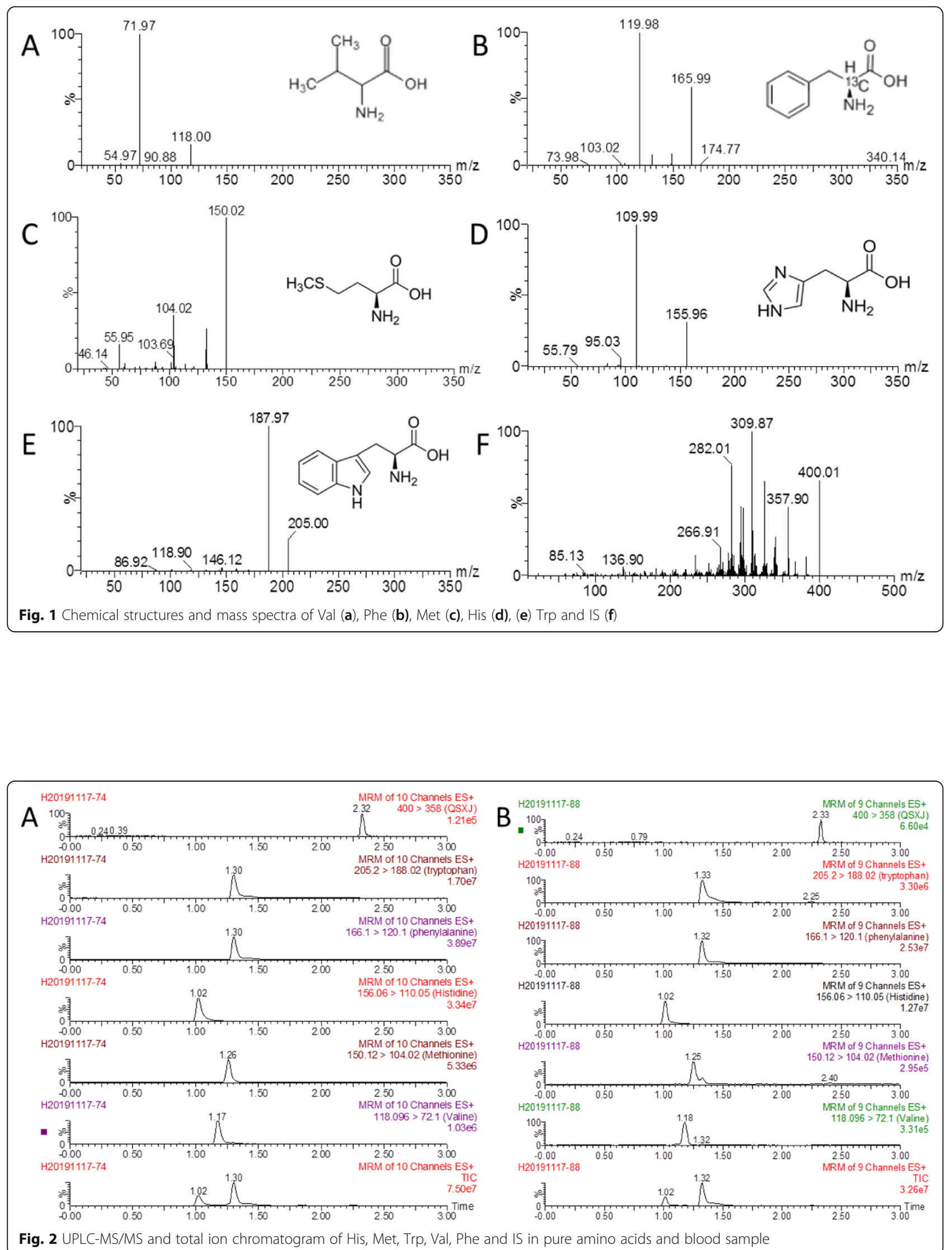
Table 2 intra-day, inter-day precision and accuracy of 5 AA in human plasma $(n=4)$

\begin{tabular}{|c|c|c|c|c|c|c|c|}
\hline \multirow[t]{2}{*}{ AA } & \multirow{2}{*}{$\begin{array}{l}\mathrm{QC} \\
(\mu \mathrm{g} / \\
\mathrm{mL})\end{array}$} & \multicolumn{3}{|l|}{ Intra-day } & \multicolumn{3}{|l|}{ Inter-day } \\
\hline & & $\begin{array}{l}\text { Mean } \pm S D \\
(\mu \mathrm{g} / \mathrm{mL})\end{array}$ & $\begin{array}{l}\text { Precision } \\
\text { (RSD \%) }\end{array}$ & $\begin{array}{l}\text { Accuracy } \\
\text { (RE \%) }\end{array}$ & $\begin{array}{l}\text { Mean } \pm \text { SD } \\
(\mu \mathrm{g} / \mathrm{mL})\end{array}$ & $\begin{array}{l}\text { Precision } \\
\text { (RSD \%) }\end{array}$ & $\begin{array}{l}\text { Accuracy } \\
\text { (RE \%) }\end{array}$ \\
\hline \multirow[t]{3}{*}{ his } & 10 & $11.21 \pm 1.21$ & 10.78 & 12.12 & $10.36 \pm 1.48$ & 14.27 & 3.62 \\
\hline & 40 & $43.23 \pm 6.41$ & 14.83 & 8.07 & $42.04 \pm 4.46$ & 10.60 & 5.09 \\
\hline & 80 & $82.06 \pm 8.59$ & 10.47 & 2.57 & $81.34 \pm 9.20$ & 11.31 & 1.68 \\
\hline \multirow[t]{3}{*}{ met } & 10 & $10.81 \pm 1.55$ & 14.35 & 8.08 & $10.30 \pm 1.44$ & 13.96 & 3.01 \\
\hline & 40 & $41.48 \pm 4.87$ & 11.73 & 3.71 & $41.43 \pm 5.44$ & 13.13 & 3.56 \\
\hline & 80 & $82.05 \pm 12.29$ & 14.97 & 2.57 & $88.00 \pm 11.05$ & 12.55 & 10.00 \\
\hline \multirow[t]{3}{*}{ val } & 10 & $11.04 \pm 1.44$ & 13.01 & 10.39 & $11.02 \pm 1.59$ & 14.46 & 10.22 \\
\hline & 40 & $41.95 \pm 1.17$ & 2.79 & 4.87 & $45.14 \pm 6.72$ & 14.88 & 12.85 \\
\hline & 80 & $80.61 \pm 3.80$ & 4.71 & 0.76 & $85.37 \pm 10.04$ & 11.76 & 6.72 \\
\hline \multirow[t]{3}{*}{$\operatorname{trp}$} & 10 & $9.55 \pm 1.26$ & 13.19 & -4.52 & $10.07 \pm 0.55$ & 5.50 & 0.69 \\
\hline & 40 & $43.46 \pm 6.05$ & 13.93 & 8.64 & $41.13 \pm 2.32$ & 5.64 & 2.84 \\
\hline & 80 & $77.89 \pm 10.16$ & 13.04 & -2.64 & $74.07 \pm 4.40$ & 5.94 & -7.42 \\
\hline \multirow[t]{3}{*}{ phe } & 10 & $10.42 \pm 1.45$ & 13.91 & 4.19 & $10.17 \pm 1.08$ & 10.58 & 1.66 \\
\hline & 40 & $36.95 \pm 5.12$ & 13.87 & -7.63 & $38.17 \pm 5.60$ & 14.67 & -4.59 \\
\hline & 80 & $78.77 \pm 5.28$ & 6.70 & -1.53 & $78.31 \pm 5.20$ & 6.63 & -2.12 \\
\hline
\end{tabular}

were all $<15 \%$ (Supplement Table 3), and the RSD values of ruggedness were all $<15 \%$ (Supplement Table 4). The results indicated that there was no significant effect on the determination of 5 AAs when the chromatographic conditions were changed slightly.

\section{Clinical indices of Hyperlipidemic and healthy subjects}

A total of 75 healthy subjects (male 32, female 43) and 83 hyperlipidemic subjects (male 40, female 43), aged between 18 and 60 years, were participated in the study. Their average ages were $37.19 \pm 9.66$ and $44.77 \pm 9.22$. The clinical indices of two groups were listed in Table 3. There were no abnormal changes in BRT indices of hyperlipidemic and healthy subjects. Although the levels of $\mathrm{RBC}$ and $\mathrm{HB}$ had risen slightly in hyperlipidemic group, they were still in the normal range. However, the blood levels of TG, TC, and LDL were all obviously increased $(P<0$. 001).

\section{Levels of 5 AAs in Hyperlipidemic and healthy subjects}

Based on the UPLC-MS/MS method, the levels of 5 essential AAs in the hyperlipidemic subjects and the healthy subjects were determined. The plasma levels of 5 essential AAs were shown in Table 4. It could be found that the mean blood levels of Val, Phe, Trp, His, and Met were different. Among them, the levels of Val and Phe were higher than those of Trp, His and Met. For hyperlipidemic subjects, the blood levels of Val and His increased and the blood level of Trp decreased.

\section{Correlations of five AAs in Hyperlipidemic and healthy subjects}

The Spearman's correlations analysis showed that there was a high correlation among Val, Phe, Trp, His, Met in healthy and hyperlipidemic subjects (Table 5). Among them, the correlation coefficient of Phe-His was the highest, followed Phe-Trp, and Phe-Val. The scatter plots of Phe-His, Phe-Trp, and Phe-Val are showed in Fig. 3.

The further correlations analysis revealed that the plasma level of TG was related to His, Phe, Trp, and Val in healthy subjects. The correlation coefficients of TGHis, TG-Phe, TG-Trp, and TG-Val were 0.24, 0.27, 0.31, and 0.25 . Nevertheless, they decreased to $0.03,0.06$, 0.17, 0.09 in hyperlipidemic subjects (Fig. 4).

\section{Discussions}

Commonly, hydrophilic interaction chromatography (HILIC) column is widely used to analyze amino acids [18, 23, 26-28]. HILIC column has hydrophilic polar stationary phase which can interact with highly polar compounds by strong hydrophilic interaction [18]. Being different from the HILIC column, C18 column has chains of 18 carbons attached to the silica beads, which has nonpolar column's environment. C18 column is the most commonly used column in analytical practice. In this study, under the same conditions of UPLC-MS/MS, we found that the C18 column had better sensitivity than the HILIC column in detection of His, Met, Trp, Val, and Phe (supplement Table 5). Therefore, an ACQUITY UPLC BEH 
Table 3 BRT and lipids indices of hyperlipidemic and healthy subjects (mean \pm SD)

\begin{tabular}{|c|c|c|}
\hline index & healthy & hyperlipidemic \\
\hline White blood cell(10*9/L) & $5.89 \pm 1.38$ & $6.07 \pm 1.31$ \\
\hline Absolute value of monocyte( $\left.10^{*} 9 / \mathrm{L}\right)$ & $0.42 \pm 0.14$ & $0.43 \pm 0.15$ \\
\hline Red blood cell $\left(10^{*} 12 / L\right)$ & $4.67 \pm 0.41$ & $4.83 \pm 0.42^{*}$ \\
\hline Hematokrit (\%) & $0.42 \pm 0.03$ & $0.43 \pm 0.05$ \\
\hline Percentage of leukomonocyte (\%) & $0.35 \pm 0.08$ & $0.35 \pm 0.07$ \\
\hline Absolute value of leukomonocyte (10*9/L) & $2.04 \pm 0.52$ & $2.13 \pm 0.54$ \\
\hline Mean corpuscular hemoglobin (pg) & $69.04 \pm 332.13$ & $30.52 \pm 1.08$ \\
\hline Mean corpuscular hemoglobin concentration (g/L) & $341.64 \pm 8.64$ & $334.53 \pm 48.27$ \\
\hline Absolute value of basophilic granulocyte $\left(10^{*} 9 / \mathrm{L}\right)$ & $0.01 \pm 0.01$ & $0.01 \pm 0.02$ \\
\hline Absolute value of eosinophils $\left(10^{*} 9 / \mathrm{L}\right)$ & $0.19 \pm 0.50$ & $0.16 \pm 0.13$ \\
\hline Hemoglobin (g/L) & $141.80 \pm 11.79$ & $147.42 \pm 13.28^{*}$ \\
\hline Blood platelet $\left(10^{*} 9 / \mathrm{L}\right)$ & $239.91 \pm 47.05$ & $238.14 \pm 49.71$ \\
\hline Thrombocytocrit (\%) & $0.26 \pm 0.05$ & $0.26 \pm 0.05$ \\
\hline Percentage of neutrophile granulocyte (\%) & $8.79 \pm 71.41$ & $0.55 \pm 0.07$ \\
\hline Absolute value of neutrophile granulocyte $\left(10^{*} 9 / L\right)$ & $3.22 \pm 1.13$ & $3.34 \pm 0.95$ \\
\hline Red cell volume distribution width (\%) & $12.72 \pm 0.57$ & $12.78 \pm 0.54$ \\
\hline Total cholesterol (mmol/L) & $4.39 \pm 0.54$ & $5.80 \pm 0.87^{* *}$ \\
\hline High density lipoprotein (mmol/L) & $1.23 \pm 0.27$ & $1.23 \pm 0.30$ \\
\hline Low density lipoprotein (mmol/L) & $2.50 \pm 0.50$ & $3.38 \pm 0.77^{* *}$ \\
\hline Triglyceride $(\mathrm{mmol} / \mathrm{L})$ & $1.01 \pm 0.31$ & $1.80 \pm 1.28^{* *}$ \\
\hline
\end{tabular}

Note: Compared with healthy subjects: ${ }^{*} P<0.05,{ }^{*} P<0.001$

C18 Column was selected. On this column, five AAs were separated well, and no interfering endogenous substances appeared in UPLC-MS/MS chromatograms. Among 5 AAs, Val, His, Phe, and Trp have one major daughter ion, while Met has three daughter ions that is 104.02, 132.92, and 55.96 in the positive ion mode. When collision energy increased, the ion 55.96 will be the major daughter ion. Compared with other ions, the MS response of 104.02 was highest and lower background noise level. Therefore, ion 104.02 was used in this study. Based on these conditions, 5 AAs had good linearity, high accuracy, and the RSD of intra-day and inter-day precision were $<15 \%$.

The developed UPLC-MS/MS method was successfully applied to determine the plasma of hyperlipidemic and healthy subjects. Hyperlipemia is a metabolic disease, and whether the AAs metabolism would be influenced in hyperlipemia is poorly studied. Theoretically, it is

Table 4 Plasma level of 5 AAs between hyperlipidemic and healthy subjects (mean \pm SD)

\begin{tabular}{llll}
\hline Fatty acid & Unit & healthy subjects & hyperlipemia subjects \\
\hline Val & $\mu \mathrm{g} / \mathrm{mL}$ & $35.34 \pm 15.64$ & $38.04 \pm 16.70$ \\
Phe & $\mu \mathrm{g} / \mathrm{mL}$ & $22.72 \pm 9.13$ & $22.41 \pm 8.45$ \\
Trp & $\mu \mathrm{g} / \mathrm{mL}$ & $17.23 \pm 4.94$ & $15.62 \pm 5.77$ \\
His & $\mu \mathrm{g} / \mathrm{mL}$ & $16.78 \pm 13.64$ & $18.35 \pm 14.49$ \\
Met & $\mu \mathrm{g} / \mathrm{mL}$ & $6.24 \pm 1.97$ & $6.21 \pm 1.97$ \\
\hline
\end{tabular}

difficult for essential AAs to maintain dynamic balance when lipid metabolism is disordered. Although the concentration of AAs in plasma can be dynamically maintained in a balance by the release of endogenous proteins and the utilization of tissues [29, 30], it is different for essential AAs because they cannot be synthesized in the body. Our results indicated that the mean blood levels of Val, Phe, Trp, His, and Met were changed in hyperlipidemic subjects. The blood levels of Val and His increased and the blood level of Trp decreased.

Table 5 Spearman's correlations analysis of 5 AAs in hyperlipidemic and healthy subjects

\begin{tabular}{llllll}
\hline AA & \multicolumn{2}{l}{ healthy subjects } & & \multicolumn{2}{l}{ hyperlipemia subjects } \\
\cline { 2 - 3 } & Coefficient & $P$ & & Coefficient & $P$ \\
\hline His-Phe & 0.94 & $<0.001$ & & 0.93 & $<0.001$ \\
His-Trp & 0.75 & $<0.001$ & 0.68 & $<0.001$ \\
His-Met & 0.40 & $<0.001$ & 0.46 & $<0.001$ \\
His-Val & 0.73 & $<0.001$ & 0.56 & $<0.001$ \\
Phe-Trp & 0.84 & $<0.001$ & 0.69 & $<0.001$ \\
Phe-Met & 0.51 & $<0.001$ & & 0.51 & $<0.001$ \\
Phe-Val & 0.72 & $<0.001$ & & 0.56 & $<0.001$ \\
Trp-Met & 0.43 & $<0.001$ & & 0.44 & $<0.001$ \\
Trp-Val & 0.55 & $<0.001$ & 0.53 & $<0.001$ \\
Met-Val & 0.59 & $<0.001$ & 0.66 & $<0.001$ \\
\hline
\end{tabular}



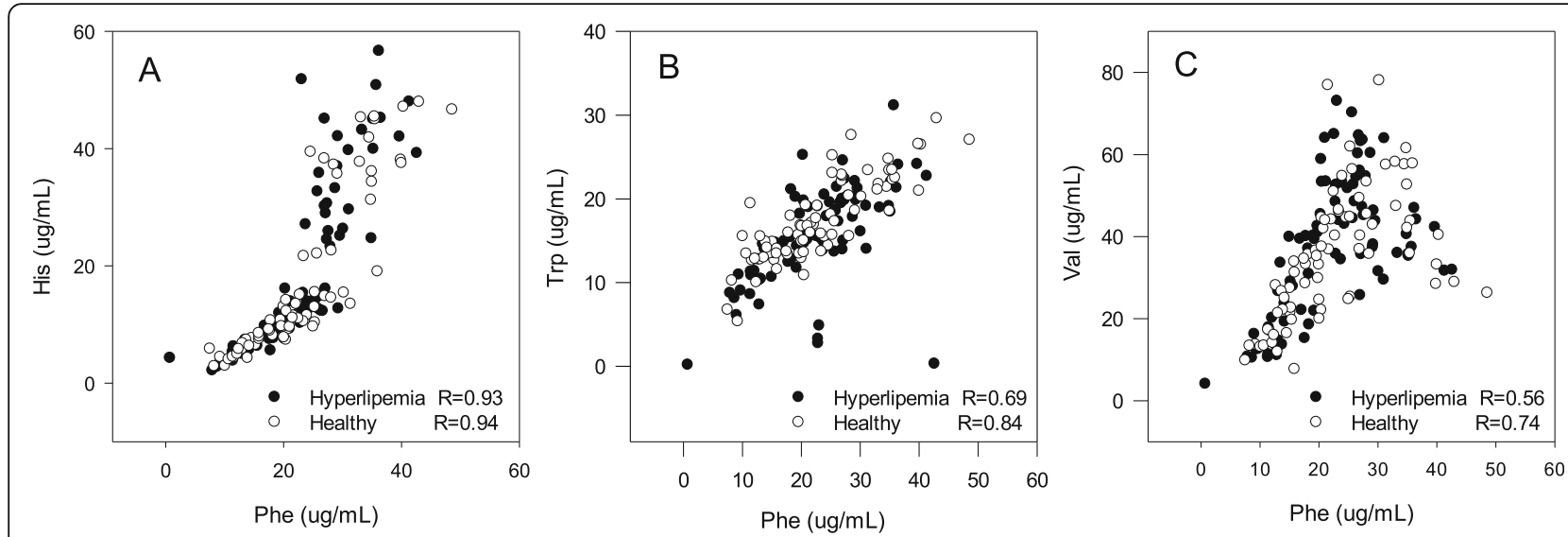

Fig. 3 Correlation of Phe with His, Trp, and Val in 83 hyperlipidemic and 75 healthy subjects, a: Phe-His, b: Phe-Trp,c: Phe-Val, R: Correlation Coefficient of Spearman's analysis
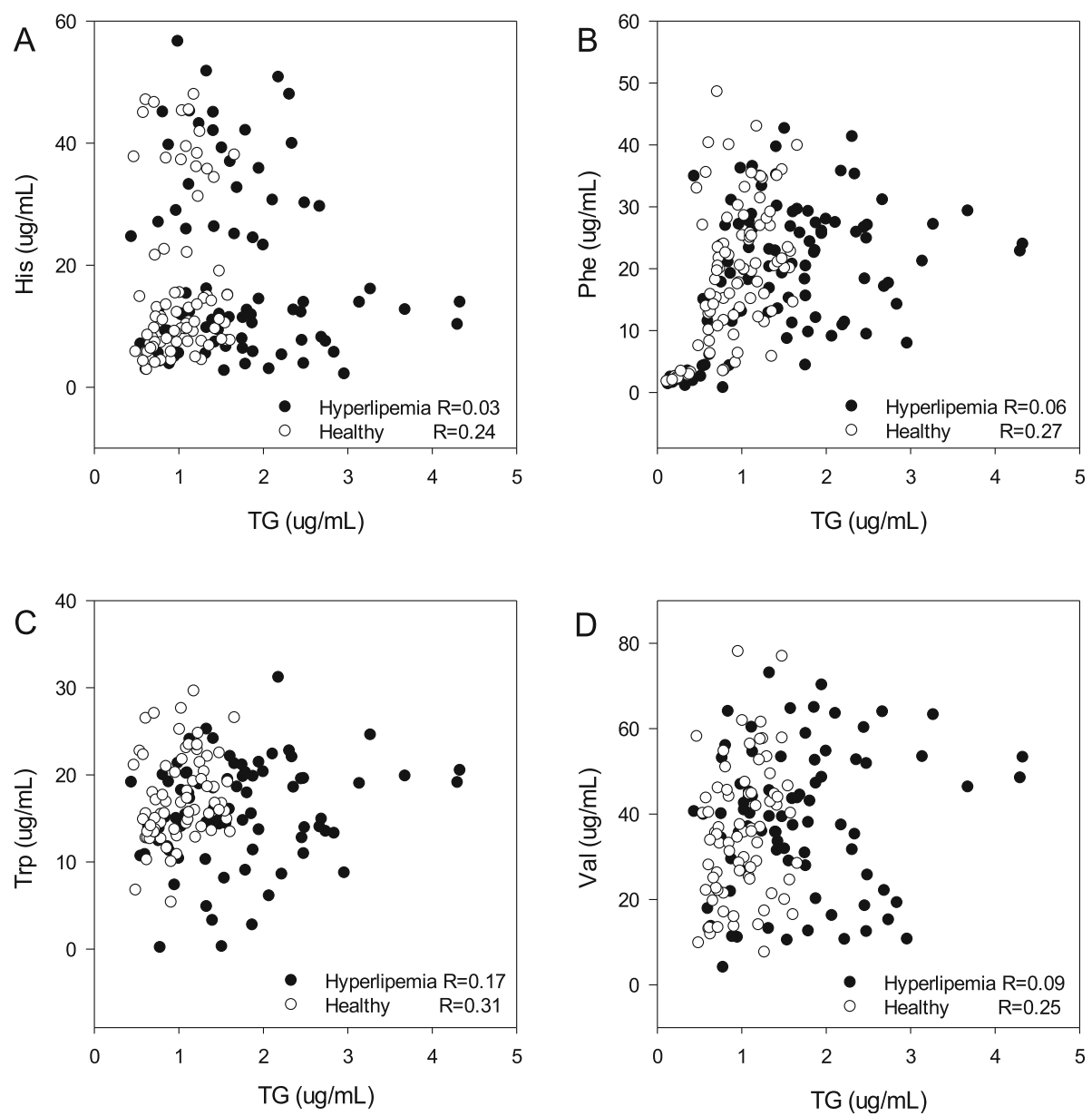

Fig. 4 Correlation of TG with His, Phe, Trp, and Val in 83 hyperlipidemic and 75 healthy subjects, a: TG-His, b: TG-Phe, c: TG-Trp, d: TG-Val; R: Correlation Coefficient of Spearman's analysis 
The Spearman's correlations analysis showed that the correlation coefficient of Phe-His was the highest, whether in the healthy subjects (0.94) or hyperlipidemic subjects (0.93). Moreover, Phe had high correlations with Trp (0.84) and Val (0.72) in healthy subjects. However, the correlation coefficients were decreased to 0.69 and 0.56 in hyperlipidemic subjects, which indicated that the level of Phe was more easily to be influenced than the other four AAs in dyslipidemia. Although the independent samples $\mathrm{T}$ test showed that there were no statistic differences for those 5AAs between healthy subjects and hyperlipidemic subjects. The correlation coefficients of AAs decreased in hyperlipemia, such as Phe-Trp (0.84/0.69), Phe-Val (0.72/0.56), His-Trp (0.75/0.68), and His-Val $(0.73 / 0.56)$, which indicated that the balance of His, Phe, Trp, and Val had been changed. Therefore, hyperlipemia or dyslipidemia may influence the metabolic balance of His, Phe, Trp, and Val.

\section{Conclusions}

A convenient, sensitive, and specified UPLC-MS/MS method was developed and validated for the measurement of the five essential AAs in human plasma: His, Phe, Trp, Met and Val, which can be determined within 3.0 min after precipitated by acetonitrile. For hyperlipidemic and healthy people, the level of Val was the highest, then was Phe, Trp, His and Met. The results of 5 AAs were significantly correlated. For healthy subjects, the plasma level of TG is related to that of His, Phe, Trp and Val. However, in hyperlipemia or dyslipidemia patients, a perturbation was uncovered in the metabolic balance of His, Phe, Trp and Val.

\section{Supplementary information}

Supplementary information accompanies this paper at https://doi.org/10. 1186/s12944-020-01216-8.

\section{Additional file 1 Supplement Table 1 The equation of calibration curves of 5 AAs in human plasma}

Additional file $\mathbf{2}$ Supplement Table $\mathbf{2}$ The extraction recovery, matrix effect and stability of 5 AA in human plasma $(n=3)$

Additional file $\mathbf{3}$ Supplement Table $\mathbf{3}$ Parameters of UPLC-MS/MS method interchanged within the range of $1-10 \%$

Additional file $\mathbf{4}$ Supplement Table $\mathbf{4}$ RSD values of ruggedness determined on two different columns and by different analysts

Additional file 5 Supplement Table 5 Peaks area of 5 AAs $(10 \mu \mathrm{g} / \mathrm{mL})$ in pure standard and blood sample determined by Hilic and BEH C18 column

\section{Abbreviations}

AAs: Amino acids; BRT: Blood routine test; GC-MS: Gas chromatography with mass spectrometry; His: Histidine; HPLC: High performance liquid chromatography; IS: Internal standard; LC-MS: Liquid chromatography tandem with mass spectrometry detection; Met: Methionine; MRM: Multiple reaction monitoring; Phe: Phenylalanine; QC: Quality-control; RE: Relative error; RSD: Relative standard deviation; TC: Total cholesterol or; TG: Triglyceride; Trp: Tryptophan; UPLC-MS/MS: Ultra-high performance liquid chromatography-tandem mass spectrometric; Val: Valine

\section{Acknowledgments}

Not applicable.

\section{Authors' contributions}

Zhibin Chen established the UPLC-MS/MS determination method. Aifang Huang carried out the sample collection and participated in the Blood biochemistry examination. Xuemei Ye participated in the development of UPLCMS/MS determination method. Feiyan Lin performed the statistical analysis. Aifang Huang and Feiyan Lin are responsible for the revision of the manuscript. Yuqian dong took part in the revision of the manuscript. Lufeng $\mathrm{Hu}$ conceived of the study, participated in the design of the study and drafted the manuscript. The author (s) read and approved the final manuscript

\section{Funding}

This study was supported by grants from the science and technology program project funds of Wenzhou (Y20180106).

\section{Availability of data and materials}

All Data is available.

\section{Ethics approval and consent to participate}

The study was approved by the Medical Ethics Committee of the First Affiliated Hospital of Wenzhou Medical University (Registry number 2016052). All procedures performed in studies involving human participants were in accordance with the ethical standards of the institutional research committee and with the 1964 Helsinki declaration and its later amendments or comparable ethical standards.

Consent for publication

Applicable.

\section{Competing interests}

The authors declare no conflict of interest.

\section{Author details}

${ }^{1}$ Department of Nephrology, The Affiliated Yueqing Hospital of Wenzhou Medical University, Yueqing, Zhejiang, China. ${ }^{2}$ School of Medicine, Zhejiang University, Zhejiang, Hangzhou, China. ${ }^{3}$ Department of Pharmacy, The First Affiliated Hospital of Wenzhou Medical University, Nanbaixiang Street, Ouhai District, Wenzhou 325000, China. ${ }^{4}$ School of Pharmacy, Wenzhou Medical University, Wenzhou 325000, China.

Received: 3 June 2019 Accepted: 1 March 2020

\section{1.}

\section{References}

1. Grajeda-Iglesias C, Aviram M. Specific amino acids affect cardiovascular diseases and Atherogenesis via protection against macrophage foam cell formation: review article. Rambam Maimonides Med J. 2018;9:e0022.

2. Pundir CS, Lata S, Narwal V. Biosensors for determination of $D$ and L- amino acids: a review. Biosens Bioelectron. 2018;117:373-84

3. Massey KA, Blakeslee $\mathrm{CH}$, Pitkow HS. A review of physiological and metabolic effects of essential amino acids. Amino Acids. 1998;14:271-300.

4. Zhao CJ, Schieber A, Ganzle MG. Formation of taste-active amino acids, amino acid derivatives and peptides in food fermentations - a review. Food Res Int. 2016;89:39-47.

5. Calderon-Santiago M, Priego-Capote F, Galache-Osuna JG, Luque de Castro MD. Determination of essential amino acids in human serum by a targeting method based on automated SPE-LC-MS/MS: discrimination between artherosclerotic patients. J Pharm Biomed Anal. 2012;70:476-84.

6. Zhao D, Lu M, Cai Z. Separation and determination of B vitamins and essential amino acids in health drinks by CE-LIF with simultaneous derivatization. Electrophoresis. 2012;33:2424-32.

7. Dumonceaux J, Goujon C, Joliot V, Briand P, Hazan U. Determination of essential amino acids involved in the CD4-independent tropism of the X4 human immunodeficiency virus type 1 m7NDK isolate: role of potential $\mathrm{N}$ glycosylations in the C2 and V3 regions of gp120. J Virol. 2001;75:5425-8.

8. Duan J, Hu B. Separation and determination of seleno amino acids using gas chromatography hyphenated with inductively coupled plasma mass spectrometry after hollow fiber liquid phase microextraction. J Mass spectrom. 2009:44:605-12. 
9. Yoon HR. Determination of plasma dibasic amino acids following trimethylsilyl-trifluoroacyl derivatization using gas chromatography-mass spectrometry. Arch Pharm Res. 2013;36:366-73.

10. Windelberg A, Arseth $O$, Kvalheim G, Ueland PM. Automated assay for the determination of methylmalonic acid, total homocysteine, and related amino acids in human serum or plasma by means of methylchloroformate derivatization and gas chromatography-mass spectrometry. Clin Chem. 2005:51:2103-9.

11. Tuma P. Rapid and sensitive determination of branched-chain amino acids in human plasma by capillary electrophoresis with contactless conductivity detection for physiological studies. Methods Mol Biol. 1972;2019:15-24.

12. Forteschi M, Sotgia S, Assaretti S, Arru D, Cambedda D, Sotgiu E, Zinellu A, Carru C. Simultaneous determination of aromatic amino acids in human blood plasma by capillary electrophoresis with UV-absorption detection. J Sep Sci. 2015;38:1794-9.

13. Parrot S, Bert L, Mouly-Badina L, Sauvinet V, Colussi-Mas J, Lambas-Senas L, Robert F, Bouilloux JP, Suaud-Chagny MF, Denoroy L, Renaud B. Microdialysis monitoring of catecholamines and excitatory amino acids in the rat and mouse brain: recent developments based on capillary electrophoresis with laser-induced fluorescence detection--a mini-review. Cell Mol Neurobiol. 2003;23:793-804.

14. Wang H, McNeil YR, Yeo TW, Anstey NM. Simultaneous determination of multiple amino acids in plasma in critical illness by high performance liquid chromatography with ultraviolet and fluorescence detection. J Chromatogr B Analyt Technol Biomed Life Sci. 2013:940:53-8.

15. Grant SL, Shulman Y, Tibbo P, Hampson DR, Baker GB. Determination of $d$ serine and related neuroactive amino acids in human plasma by highperformance liquid chromatography with fluorimetric detection. J Chromatogr B Analyt Technol Biomed Life Sci. 2006;844:278-82.

16. Gatti R, Gioia MG. Liquid chromatographic fluorescence determination of amino acids in plasma and urine after derivatization with phanquinone. Biomed Chromatogr. 2008;22:207-13.

17. Badiou S, Lehmann S, Cristol JP, Bellet H. Determination of plasma amino acids by fluorescent derivatization and reversed-phase liquid chromatographic separation. Clin Lab. 2004;50:153-8.

18. Wen Y, Yuan X, Qin F, Zhao L, Xiong Z. Development and validation of a hydrophilic interaction ultra-high-performance liquid chromatographytandem mass spectrometry method for rapid simultaneous determination of 19 free amino acids in rat plasma and urine. Biomed Chromatogr. 2019; 33:e4387.

19. Li R, Liu P, Liu P, Tian Y, Hua Y, Gao Y, He H, Chen J, Zhang Z, Huang Y. A novel liquid chromatography tandem mass spectrometry method for simultaneous determination of branched-chain amino acids and branchedchain alpha-keto acids in human plasma. Amino Acids. 2016;48:1523-32.

20. Harder U, Koletzko B, Peissner W. Quantification of 22 plasma amino acids combining derivatization and ion-pair LC-MS/MS. J Chromatogr B Analyt Technol Biomed Life Sci. 2011;879:495-504.

21. Gu L, Jones AD, Last RL. LC-MS/MS assay for protein amino acids and metabolically related compounds for large-scale screening of metabolic phenotypes. Anal Chem. 2007;79:8067-75.

22. Dong M, Qin L, Xue J, Du M, Lin SY, Xu XB, Zhu BW. Simultaneous quantification of free amino acids and 5 '-nucleotides in shiitake mushrooms by stable isotope labeling-LC-MS/MS analysis. Food Chem. 2018;268:57-65.

23. Domingues DS, Crevelin EJ, de Moraes LA, Cecilio Hallak JE, de Souza Crippa JA, Costa Queiroz ME. Simultaneous determination of amino acids and neurotransmitters in plasma samples from schizophrenic patients by hydrophilic interaction liquid chromatography with tandem mass spectrometry. J Sep Sci. 2015;38:780-7.

24. Last AR, Ference JD, Menzel ER. Hyperlipidemia: drugs for cardiovascular risk reduction in adults. Am Fam Physician. 2017:95:78-87.

25. Li G, Zhou L, Ouyang W, Xuan M, Lu L, Li X, Wen Z, Chen X. A core outcome set for clinical trials of Chinese medicine for hyperlipidemia: a study protocol for a systematic review and a Delphi survey. Trials. 2019;20: 14.

26. Bocian S, Skoczylas M, Buszewski B. Amino acids, peptides, and proteins as chemically bonded stationary phases--a review. J Sep Sci. 2016;39:83-92.

27. Brack A. From interstellar amino acids to prebiotic catalytic peptides: a review. Chem Biodivers. 2007:4:665-79.

28. Sakamoto T, Furukawa S, Nishizawa T, Fukuda M, Sasaki M, Onozato M, Uekusa S, Ichiba H, Fukushima T. Succinimidyl (3-[(benzyloxy)carbonyl]-5oxo-1,3-oxazolidin-4-yl) acetate on a triazole-bonded phase for the separation of dl-amino-acid enantiomers and the mass-spectrometric determination of chiral amino acids in rat plasma. J Chromatogr A. 2019; 1585:131-7.

29. Abbasi IHR, Abbasi F, Abd El-Hack ME, Abdel-Latif MA, Soomro RN, Hayat K, Mohamed MAE, Bodinga BM, Yao J, Cao Y. Critical analysis of excessive utilization of crude protein in ruminants ration: impact on environmental ecosystem and opportunities of supplementation of limiting amino acids-a review. Environ Sci Pollut Res Int. 2018;25:181-90.

30. Karkela JT. Critical evaluation of postmortem changes in human autopsy cisternal fluid. Enzymes, electrolytes, acid-base balance, glucose and glycolysis, free amino acids and ammonia. Correlation to total brain ischemia. J Forensic Sci. 1993;38:603-16.

\section{Publisher's Note}

Springer Nature remains neutral with regard to jurisdictional claims in published maps and institutional affiliations.
Ready to submit your research? Choose BMC and benefit from:

- fast, convenient online submission

- thorough peer review by experienced researchers in your field

- rapid publication on acceptance

- support for research data, including large and complex data types

- gold Open Access which fosters wider collaboration and increased citations

- maximum visibility for your research: over $100 \mathrm{M}$ website views per year

At BMC, research is always in progress.

Learn more biomedcentral.com/submissions 